\title{
Investigation of cascadability of add-drop multiplexers in OTDM systems
}

Jepsen, Kim Stokholm; Poulsen, Henrik Nørskov; Clausen, Anders; Buxens Azcoaga, Alvaro Juan; Stubkjær, Kristian

Published in:

Optical Communication, 1998. 24th European Conference on

Link to article, DOI:

10.1109/ECOC.1998.732751

Publication date:

1998

Document Version

Publisher's PDF, also known as Version of record

Link back to DTU Orbit

Citation (APA):

Jepsen, K. S., Poulsen, H. N., Clausen, A., Buxens Azcoaga, A. J., \& Stubkjær, K. (1998). Investigation of cascadability of add-drop multiplexers in OTDM systems. In Optical Communication, 1998. 24th European Conference on (Vol. 1, pp. 619-620). IEEE. https://doi.org/10.1109/ECOC.1998.732751

\section{General rights}

Copyright and moral rights for the publications made accessible in the public portal are retained by the authors and/or other copyright owners and it is a condition of accessing publications that users recognise and abide by the legal requirements associated with these rights.

- Users may download and print one copy of any publication from the public portal for the purpose of private study or research.

- You may not further distribute the material or use it for any profit-making activity or commercial gain

- You may freely distribute the URL identifying the publication in the public portal 


\title{
INVESTIGATION OF CASCADABILITY OF ADD-DROP MULTIPLEXERS IN OTDM SYSTEMS
}

\author{
K.S. Jepsen, H.N. Poulsen, A.T. Clausen, A. Buxens, K.E. Stubkjaer \\ Department of Electromagnetic Systems, Technical University of Denmark, DK-2800 Lyngby, Denmark \\ Phone: +45 4525 3782, Fax: +45 4593 1634, E-mail: kje@emi.dtu.dk \\ Abstract: The influence of coherent cross-talk on the cascadability of add-drop multiplexers in OTDM systems is \\ analysed theoretically using moment generating functions. Calculations are validated by experiments.
}

\section{Introduction}

All-optical add-drop multiplexing is a key function in OTDM systems and constitutes an important step in making OTDM a practical technology. The first demonstration of high-speed OTDM LAN systems employing add-drop multiplexers (ADMs) has recently been shown [1]. The aim of this work is to analyse system requirements for cascaded add-drop multiplexers in OTDM systems, as set by coherent cross-talk [2]. As illustrated in Fig. 1, add-drop multiplexing gives rise to intra-channel coherent cross-talk if the add timeslot is not adequately cleared by the ADM prior to inserting the add signal [3]. Additionally, the tails of the added pulses leak into the neighbouring timeslots, resulting in inter-channel coherent cross-talk which is a feature specific to OTDM. In addition to the calculated results, we present experimental validation of the applied model for a $10 \mathrm{~Gb} / \mathrm{s} \mathrm{RZ}$ signal with cross-talk terms from up to three independent sources.

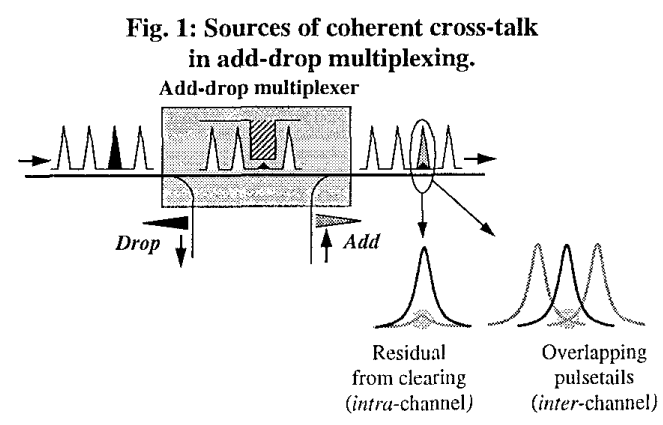

Theoretical model and experimental verification

The theoretical framework is the method of moment generating functions (MGF) [4]. The coherent cross-talk modifies the MGF to include additional product terms of the form $\mathrm{I}_{0}\left(2 \sqrt{p_{s i g} p_{j}} \cdot\right.$ otherterms $)$, where is the modified Bessel function, for all the interfering channels $j$. The system BER is evaluated by applying the saddle-point approximation [5] to the MGF for calculating the probability in the tails of the probability distributions.

Experimentally, the influence of coherent cross-talk on the receiver sensitivity is analysed in a simple experiment: The $10 \mathrm{~Gb} / \mathrm{s} \mathrm{RZ}$ signal is obtained by externally modulating pulses from a $10 \mathrm{GHz}$ gain-switched DFB laser $(\lambda=1556 \mathrm{~nm}$, FWHM 8ps, $\Delta t \Delta B \sim 0.8$ ). External cavity lasers provide up to three independent $\mathrm{CW}$ signals $(\lambda=1556 \mathrm{~nm})$ for introduc- ing coherent cross-talk in the signal. The signal is received in an optically pre-amplified $10 \mathrm{~Gb} / \mathrm{s}$ receiver, and the resulting power penalty for 1,2 and 3 cross-talk signals (identical power and polarisation) is shown in Fig. 2. The experiments simulate the influence of overlapping pulse tails due to pedestals (characterised by the pulse-tail extinction ratio relative to the pulse peak, PTER) in an OTDM signal. Calculations simulating the above experiment are also shown in the figure. The agreement between measurements and calculations is very good both in terms of trends and absolute values and the validity of the model is verified.

Fig. 2: Experimental and calculated power penalty vs. PTER in the case of $1(0), 2(\Delta)$ and $3(\delta) C W$ interferers.

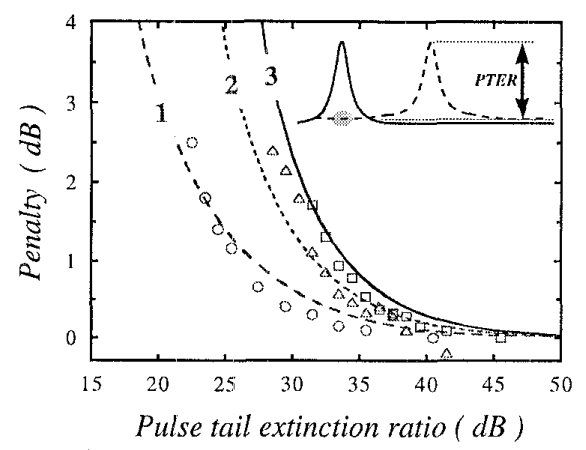

Cascadabilty of add-drop multiplexers

Calculations are carried out using the following system parameters: The OTDM signal is passively multiplexed from $N$ independent $10 \mathrm{~Gb} / \mathrm{s} \mathrm{RZ}$ signals $\left(R_{\text {ext }}=13 \mathrm{~dB}\right)$. The $\operatorname{sech}^{2}$ pulses have a FWHM equal to $1 / 4$ of the timeslot of the aggregate bit-rate. The pulses are further characterised by a pedestal, as described above. In the add-drop multiplexer the add timeslot is suppressed by $25 \mathrm{~dB}$ (termed the intra-timeslot suppression ratio, ITSR) across the entire width of the time slot and a new channel is added into the cleared timeslot. At the receiver the signal is demultiplexed to $10 \mathrm{~Gb} / \mathrm{s}$ and the sensitivity is calculated.

In the first set of calculations the add-signals are repeatedly inserted into the same timeslot (Fig. 3). As illustrated in the figure, each successive clearing further suppresses the previous signals, and as a result the total cross-talk power is effectively bounded. Therefore, no limitation to the cascadability is expected for the add channel. Calculated power penalties versus number of cascaded ADMs are shown in Fig. 3 with the PTER as parameter and for both $4 \times 10$ and 
$8 \times 10 \mathrm{~Gb} / \mathrm{s}$ signals. Several distinctive features are seen: First, the results for the add channel and neighbouring channels are qualitatively different. The add channel suffers an initial multiplexing penalty (zero cascaded nodes) followed by a constant penalty for add-drop multiplexing, as described above. In contrast, the neighbouring channels suffer from an increasing number of cross-talk terms due to the pulse tails from the add signals. The most severely affected channels are the two nearest neighbours since they are affected by the flanks of the add pulses while the other neigh bours are only affected by the pedestals. Further, the calculations show that the PTER is a key parameter for cascading ADMs; a major improvement in the cascadability is seen for just $5 \mathrm{~dB}$ improvement of the pulse pedestals. The last figure indicates that although the penalty is a little higher for the $80 \mathrm{~Gb} / \mathrm{s}$ signal than for the $40 \mathrm{~Gb} / \mathrm{s}$ signal, the requirements to the pulse pedestals are only moderately affected by increasing the level of aggregation.

Fig. 3: Cascading of ADMs, adding repeatedly into same timeslot. a.) Previous signals in add timeslot are further suppressed on each clear/add. b.) Calculated power penalty for $4 \times 10 \mathrm{~Gb} / \mathrm{s}$ and $8 \times 10 \mathrm{~Gb} / \mathrm{s}$ OTDM signals with PTER as parameter. Clearing efficiency by $A D M$ is $25 \mathrm{~dB}$.
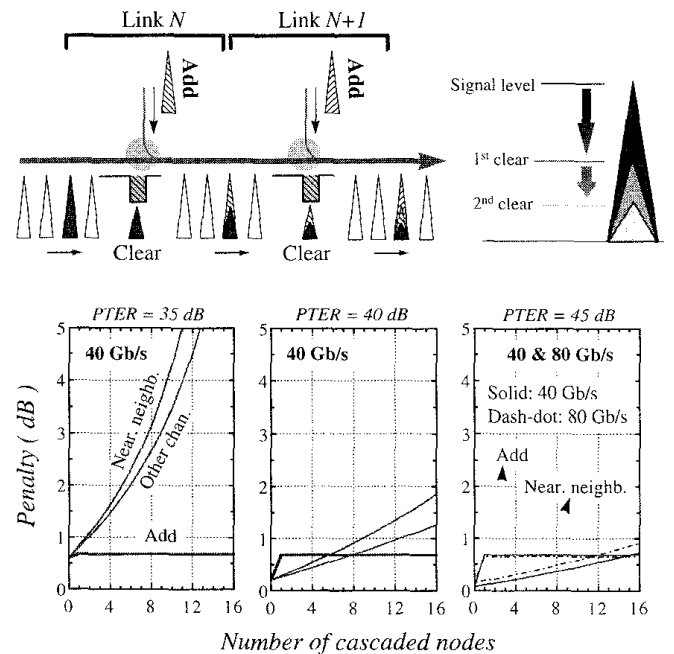

Fig. 5: Combined requirements to PTER and ITSR for worst case node in circular add-drop for $N=4,8$ and 16 .

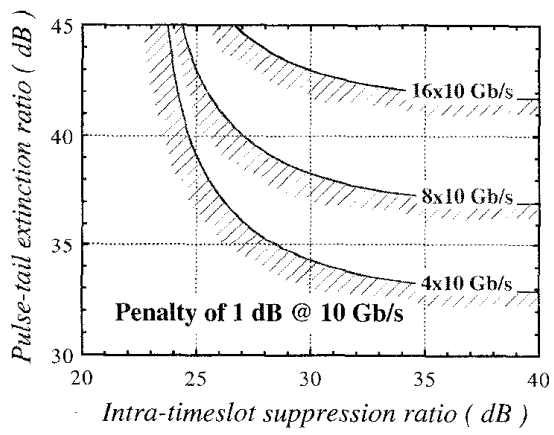

In most circumstances, the add-drop multiplexing actually plays an important role in reducing the coherent noise buildup due to pulse tail overlap. As an example of this, Fig. 4 shows the evolution of power penalty for one of the channels in the case of 'circular' add and drop (add-drop channel shifted by one timeslot for every add) for a $4 \times 10 \mathrm{~Gb} / \mathrm{s}$ signal. The penalty is basically reset to the level of the 'addpenalty' by the clear/add process at the beginning of each cycle, after which the penalty increases, before once again being reset. The cross-talk terms for the worst case node essentially consist of one residual pulse from the most recent 'clearing' and $N-1$ pulse tails from the other channels. Thus, this worst-case penalty depends both on the PTER and on the ITSR, as illustrated in Fig. 5. The figure shows the combined requirements for circular add-drop multiplexing (penalty $<1 \mathrm{~dB}$ ) to the pulse quality and the clearing efficiency, in terms of PTER and ITSR of the ADM. Results for a $4 \times 10,8 \times 10$ and $16 \times 10 \mathrm{~Gb} / \mathrm{s}$ signal $(N=4,8,16)$ are shown. As an example, for a ring where 4 nodes communicate mutually (one timeslot allocated for each connection), $N=6$. Add-drop experiments at $4 \times 10 \mathrm{~Gb} / \mathrm{s}$ with a single ADM [6] clearly show that adequate pulse quality and clearing of the add timeslot can be obtained, so that cascading of ADMs is feasible for at least $4 \times 10 \mathrm{~Gb} / \mathrm{s}$ signals, e.g., in a ring configuration as described above.

Fig. 4: Calculated power penalty in the case of $40 \mathrm{~Gb} / \mathrm{s}$ 'circular' add-drop (add-drop channel shifted by one timeslot for every add).

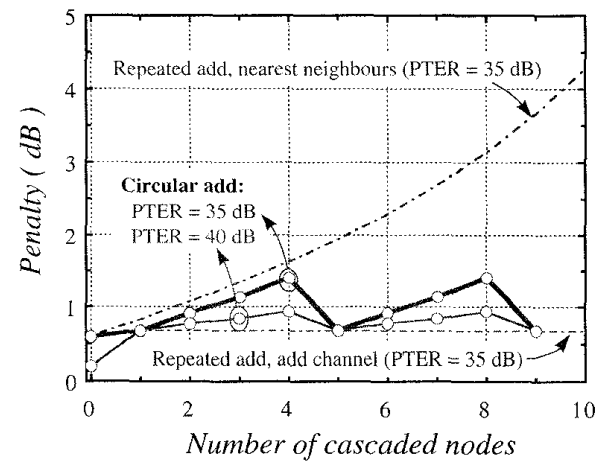

Conclusion

The cascadability of add-drop multiplexers in OTDM systems has been investigated theoretically. The calculations show that the residual power level in the pulse-tails is a crucial parameter and that the clearing of the add timeslot plays an important role in extending the cascadability of add-drop multiplexers.

\section{Acknowledgement}

This work is in part carried out within the ACTS project HIGHWAY (AC067) under the European Commission.

\section{References}

/1/ P. Gunning, Electron. Lett., v. 33, p. 488 (1998).

/2/ J. Gimlett, Photon. Technol. Lett., v. 29, p. 990 (1990)

13/ K. Jepsen, Techn. Dig. CLEO'97, CThP3 (1997).

14/ R. Fayth, IEE Proceed., v. 137, p. 391 (1990).

151 C. Helstrom, Tr. Aero. Elec. Syst., v. 14, p. 630 (1978).

16/ K. Jepsen, Techn. Dig. OFC'97, ThN2 (1997). 